best prospects for industrial production of microbial protein. The returns from gaseous hydrocarbon fermentations are compromised at present, because the very much cheaper cost of the substrate is laid against less favourable growth and nutritive characteristics. Nevertheless, both engineering and microbiological technologies can be expected to improve this position.

Apart from hydrocarbons, various plant materials have attracted attention in the contexts of SCP and sugar production. Thus, numerous schemes, many of them patented, have been suggested for the microbial utilization of wood, sulphite waste liquor, bagasse and related materials. Fodder yeast production on sulphite waste liquor is one of the few successful processes of this type to emerge ; and the attempts to produce glucose syrups from cellulose have been discussed previously in this column. The development of an SCP process based on wood hydrolysis products has also received attention and Russian interests in this field have been made known recently (Nature New Biology, 230, 100 ; 1971). Kobayashi's review (Process Biochem., 6, 19; 1971) of chemical wood hydrolysis and the utilization of wood sugars for fermentation makes interesting reading for those who see this process as a cheap source of cellulose.

\section{NUCLEAR REACTORS}

\section{Void Swellings}

from a Correspondent

THE fact that atoms are displaced from their normal sites within a solid during irradiation with fast neutrons from nuclear reactors is well known and has provided a fruitful field of research since the early 1940s. It was not until 1966, however, that C. Cawthorne and I. Fulton at the UK Atomic Energy Authority's fast reactor station at Dounreay discovered a new radiation damage phenomenon, namely "void formation".

Careful electron microscopical studies of fast reactor fuel cladding from the Dounreay Fast Reactor (DFR) revealed a high density of small cavities with diameters of $100 \AA$; such cavities were shown to be essentially empty and were therefore called voids. The creation of such cavities within a solid implies that the external dimensions of the solid must increase in order that the total quantity of solid material stays constant. It was soon found that certain reactor components had indeed increased their external dimensions and consequently suffered a density decrease.

The phenomenon of void swelling, as it has come to be known, was not expected, chiefly because before the advent of fast reactors neutron irradiation to high doses at elevated temperatures was almost impossible. The consequences of such swelling must be taken into account in the design and operation of fast reactors; for, as a result of nonuniform damage rates throughout a reactor, some key components are expected to suffer distortion as a consequence of differential swelling. Such distortions must be minimized by operational or engineering modifications which may carry economic penalties, or alternatively by using different materials which exhibit greater resistance to swelling.

The first major conference on void swelling was organized by the British Nuclear Energy Society at the University of Reading on March 24 and 25. The conference was opened by a review of neutron induced voidage by Drs K. Q. Bagley, J. I. Brammon and C. Cawthorne (UKAEA, Dounreay) which presented some of the latest results and proved most valuable. Much of the current experimental work on void formation has been carried out using charged particles from accelerators or by electron irradiation in the high voltage electron microscope. Such techniques have been able to simulate the void swelling that occurs after many years irradiation in reactors in times of less than a day and for this reason two complete sessions at the meeting were devoted to these studies; reviews were presented by Drs R. S. Nelson, D. J. Mazey and J. A. Hudson (AERE, Harwell) and $\mathrm{Dr}$ D. I. R. Norris (CEGB Berkeley Nuclear Laboratories).

The principal results to emerge from the meeting were that materials such as well annealed nickel, copper and stainless steel all show significant void formation. For instance, swellings up to about 10 per cent were predicted to occur in commercial fast reactor components after irradiation times equivalent to the life dose of the fuel, but if these same materials are previously cold worked they show reduced swellings. Perhaps the most significant development from both reactor and accelerator studies is that alloys such as Nimonic PE16 exhibit dramatic resistance to swelling. For instance, after irradiation to high doses at $525^{\circ} \mathrm{C}$ the swelling is more than an order of magnitude smaller than for steel. This result is thought to be a consequence of the very fine precipitates within PE16 which cause recombination of the displaced atoms, together with the fact that such precipitates act to pin the radiation induced dislocation network on a very fine scale.

\title{
Synthesis of $\mathrm{SO}_{2}$ Metal Ion Clusters
}

THE pioneers of the study of ions in the gas phase, such as Thomson and Aston in 1910 to 1920 , expected the charged species to be very similar in type to known neutral species, from which they would be more or less directly formed. Although they had one or two surprises which were contrary to this expectation, they would surely be amazed at the development of the investigations in just over half a century since their own work was carried out. This is strikingly underlined by an account of work by Tang, Munkelwitz and Castleman in next Monday's Nature Physical Science.

Tang and his colleagues at Brookhaven National Laboratory investigated the results of introducing gaseous $\mathrm{Na}^{+}$ions into a chamber filled to a pressure of 4 torr with $\mathrm{SO}_{2}$. Ionic species extracted from the other end of the chamber showed stable combinations of up to five molecules of $\mathrm{SO}_{2}$ into the ion. A similar effect with $\mathrm{H}, \mathrm{O}$ was confirmed, and a mixture of the two vapours was found to yield all possible combinations of the two adducts around the $\mathrm{Na}^{+}$. Further work, to be described fully later, showed similar effects when $\mathrm{NO}^{+}$was substituted for $\mathrm{Na}^{+}$. A great deal of work will evidently be necessary before the full story of the structure, relative stability and rates of formation of these species has been told.

The interest of such an extension of knowledge of ion chemistry reaches out in many directions. It is expected to have a bearing on the study of coordination complexes in liquid and solid phases. Studies of mobilities of ions in gas and liquid phase alike will have to take note of such effects, providing links with electrochemistry and with the study and varying uses of electric discharges. A very important and obvious similarity to the conditions of the ionosphere and upper atmosphere is pointed out by the authors, and this may indeed be a source of inspiration for the work. Studies of possible ion-molecule reactions are equally relevant, however, to the high pressure environment of a gas-cooled atomic reactor. A further branch of interest may lie in the study of the atmosphere which we breathe.

As much as a decade ago, Westermark published (Nature, 189, 910; 1961) observations of the ionic content of the atmosphere caused by internal combustion energies and other common devices. Further such studies might show a population of ions of most surprising constitution and stability, perhaps tending towards the characteristics of an aerosol. 